\title{
Amyloid- $\beta$ peptides in cerebrospinal fluid of patients with dementia with Lewy bodies
}

Inger van Steenoven ${ }^{1^{*}}$ (D), Wiesje M. van der Flier ${ }^{1,2}$, Philip Scheltens ${ }^{1}$, Charlotte E. Teunissen ${ }^{3}$ and Afina W. Lemstra ${ }^{1}$

\begin{abstract}
Background: One of the major challenges in diagnosing dementia with Lewy bodies (DLB) is the common comorbid presence of amyloid pathology. To understand the putative role of altered amyloid- $\beta$ (A $\beta$ ) metabolism in dementia with $D L B$, we analyzed levels of different cerebrospinal fluid (CSF) $A \beta$ peptides (A $338, A \beta 40, A \beta 42)$ in DLB, Alzheimer's disease (AD), and cognitively normal controls.

Methods: CSF from patients with DLB ( $n=72$; age $68 \pm 6$ years; 10\%F; Mini-mental State examination (MMSE) $23 \pm$ 4), AD ( $n=38$; age $68 \pm 6$ years; $8 \%$ F; MMSE $22 \pm 5$ ), and cognitively normal controls ( $n=38$; age $67 \pm 7$ years; $13 \% F$; MMSE $29 \pm 2$ ) was analyzed using the Meso Scale Discovery assay for human A $\beta$ peptides. We performed general linear models to compare CSF A $\beta$ peptide levels between groups. Associations between CSF A $\beta$ peptides and MMSE score at baseline and longitudinal changes over time were assessed with linear mixed models.

Results: For all three CSF A $\beta$ peptides and compared to controls (Aß38 $2676 \pm 703$ pg/ml, A $3406243 \pm 1500$ pg/ml, and $A \beta 42692 \pm 205 \mathrm{pg} / \mathrm{ml})$, we observed lower levels in DLB (Aß38 $2247 \pm 638, A \beta 405432 \pm 1340$, and Aß42 $441 \pm$ $185, p<0.05)$, whereas AD patients showed only lower A 42 levels $(304 \pm 71, p<0.001)$. The observed differences in $A \beta 38$ and $A \beta 40$ were independent of co-morbid AD pathology (CSF tau/A $\beta 42>0.52$ ) and APOE genotype. Finally, lower $A \beta$ peptide levels were associated with lower MMSE score $(\beta=1.02-1.11, p<0.05)$.

Conclusion: We demonstrated different profiles of CSF A $\beta$ reduction in DLB and AD. In particular, while AD is characterized by an isolated drop in $A \beta 42$, DLB comes with reductions in $A \beta 38, A \beta 40$, and $A \beta 42$. This suggests that amyloid metabolism is affected in DLB, even in the absence of co-morbid AD pathology.
\end{abstract}

Keywords: Cerebrospinal fluid, Dementia with Lewy bodies, Amyloid- $\beta$ peptides, Co-morbid Alzheimer's disease pathology

\section{Background}

Dementia with Lewy bodies (DLB) is the second most common neurodegenerative disease in the elderly after Alzheimer's disease (AD), accounting for up to $20 \%$ of the dementia cases [1]. Next to dementia, core features of DLB are parkinsonism, visual hallucinations, fluctuations in cognition and attention, and rapid eye movement (REM) sleep behavior disorder (RBD) [2]. DLB is

\footnotetext{
* Correspondence: i.vansteenoven@amsterdamumc.nl

${ }^{1}$ Alzheimer Center Amsterdam, Department of Neurology, Amsterdam Neuroscience, Vrije Universiteit Amsterdam, Amsterdam UMC, De Boelelaan 1118, 1081 HV Amsterdam, The Netherlands

Full list of author information is available at the end of the article
}

characterized neuropathologically by the accumulation of $\alpha$-synuclein aggregates in Lewy bodies and Lewy neurites throughout the brain [3]. In addition, DLB patients often have some degree of concomitant ADrelated pathology, i.e., extracellular amyloid- $\beta$ (A $\beta$ ) aggregation and intracellular tau deposition, such that up to $50 \%$ of DLB patients have a high-level AD pathology $[4,5]$ and approximately $25 \%$ have an AD profile in cerebrospinal fluid (CSF) [6]. Several studies demonstrated that co-morbid AD pathology influences clinical diagnostic accuracy [7] and is related with a more severe disease course in DLB $[5,8-10]$. However, the

(c) The Author(s). 2019 Open Access This article is distributed under the terms of the Creative Commons Attribution 4.0 International License (http://creativecommons.org/licenses/by/4.0/), which permits unrestricted use, distribution, and reproduction in any medium, provided you give appropriate credit to the original author(s) and the source, provide a link to the Creative Commons license, and indicate if changes were made. The Creative Commons Public Domain Dedication waiver (http://creativecommons.org/publicdomain/zero/1.0/) applies to the data made available in this article, unless otherwise stated. 
pathophysiological processes underlying the co-existence of AD pathology in DLB are still unknown.

Several lines of evidence suggest that an imbalance between production and clearance of $A \beta$ is the initiating factor that contributes to AD pathology $[11,12] . A \beta$ is a proteolytic cleavage product of amyloid precursor protein (APP). In the amyloidogenic pathway, cleavage by $\beta$ - and $\gamma$-secretase results in different $A \beta$ peptides, ranging from 38 to 43 amino acids. The precise location and the number of cleavages determine the ultimate length of the $A \beta$ peptide [13]. The most abundant $A \beta$ peptides in CSF are $A \beta 38, A \beta 40$, and $A \beta 42$ [14]. CSF $A \beta$ peptide levels might reflect to some extent the dysregulation of $A \beta$ metabolism (production and clearance) and $A \beta$ aggregation in the brain. $A \beta 42$ is prone to deposition in amyloid plaques. Reduced levels of $A \beta 42$ in CSF are thought to reflect $A \beta 42$ sequestration in amyloid plaques in the brain $[15,16]$. The shorter $A \beta$ peptides, $A \beta 38$ and $\mathrm{A} \beta 40$, are less prone to aggregate and their CSF concentrations rather reflect production of $A \beta$ peptides from APP by $\beta$ - and $\gamma$-secretases [17]. In contrast with AD, reduced CSF levels of all three A $\beta$ peptides in DLB have been reported in studies with small numbers of included DLB patients [18-23]. However, CSF A $\beta$ peptides have not yet been validated in large, well-characterized clinical cohorts, and none of these studies addressed the issue of co-morbid AD pathology in DLB.

In the present study, we aim to (1) characterize the levels of three different CSF $A \beta$ peptides $(A \beta 42, A \beta 40$, and $A \beta 38)$ in DLB and compare this with levels in $A D$ and cognitively normal controls and (2) investigate whether evidence of $A D$ pathology defined by a CSF profile compatible with $\mathrm{AD}$ influences CSF levels of $\mathrm{A} \beta$ peptides in DLB patients. Finally, we studied whether specific CSF $A \beta$ peptides were associated with cognitive decline in DLB.

\section{Methods \\ Study population}

We included 72 patients with a diagnosis of probable DLB and matched them for age and sex with 38 patients with a diagnosis of probable AD and 38 subjects with subjective cognitive decline (SCD) who served as controls (Fig. 1). The abovementioned patients and controls were selected from the Amsterdam Dementia Cohort [25], consisting of patients who were assessed at the Alzheimer Center Amsterdam between January 2000 and December 2017, based on the availability of CSF. All selected patients and controls underwent an extensive standardized and multidisciplinary workup, as part of the routine clinical practice, including medical history, physical and neurological examinations, neuropsychological evaluation, electroencephalography (EEG), brain magnetic resonance imaging (MRI), and laboratory tests including lumbar puncture and apolipoprotein $\mathrm{E}$ (APOE) genotyping. Biomaterial is available for $67 \%$ of all patients in the Amsterdam Dementia Cohort [25]. Diagnoses were made in a multidisciplinary consensus meeting. DLB was diagnosed according to the clinical diagnostic consensus criteria for probable DLB [2]. The diagnosis of DLB was supported by (123) I-FP-CIT-SPECT (DATSPECT) findings showing presynaptic dopaminergic

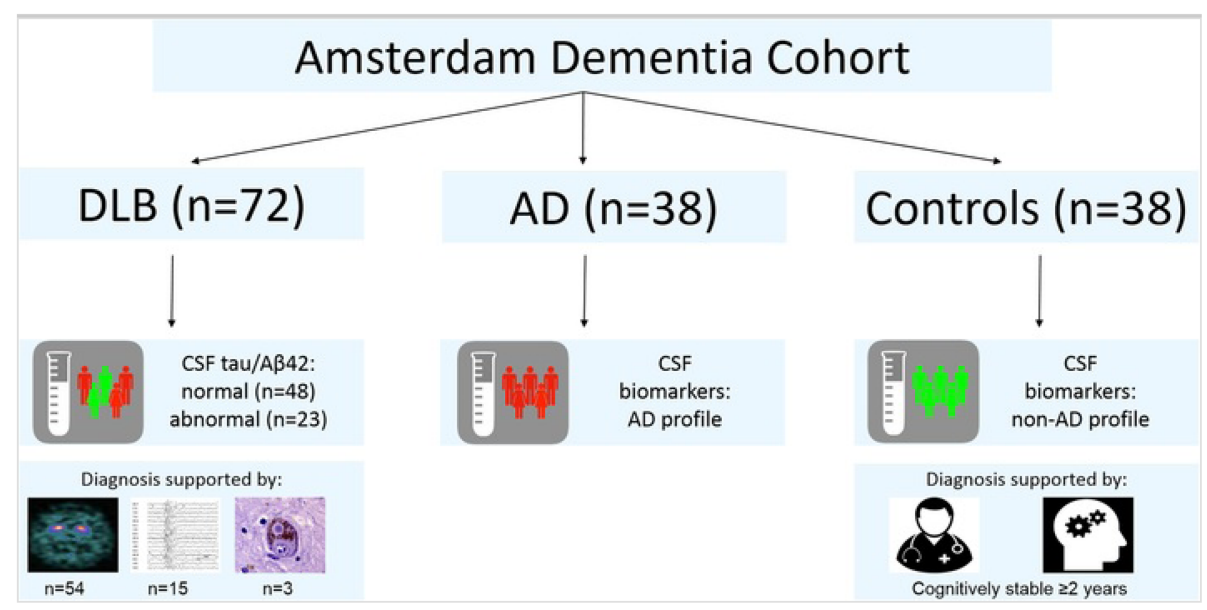

Fig. 1 Flow chart of patient selection. We selected 72 patients with a diagnosis of probable DLB and matched them for age and sex with 38 patients with a diagnosis of probable $A D$ and 38 patients with subjective cognitive decline (SCD) who served as control subjects from the Amsterdam Dementia Cohort. DLB patients were stratified into two groups: DLB patients with an AD CSF profile (CSF tau/A $\beta_{1-42} \geq 0.52$ [24]; DLB $A D+, n=23)$ and DLB patients with a normal CSF profile (CSF tau/A $\left.\beta_{1-42}<0.52 ; D L B A D-, n=48\right)$. The diagnosis of DLB was supported by (123) I-FP-CIT-SPECT (DAT-SPECT) findings showing presynaptic dopaminergic deficits $(n=54,75 \%)$ or by slow-wave activity on EEG $(n=15,21 \%)$, or was confirmed at autopsy $(n=3,4 \%)$. All AD patients had a CSF profile compatible with AD. All controls had normal AD biomarker levels and preserved normal cognitive function on neuropsychological testing for at least 2 years after first presentation at the memory clinic 
deficits $(n=54,75 \%)$ or by slow-wave activity on EEG $(n=15,21 \%)$, or was confirmed at autopsy $(n=3,4 \%)$. Patients with AD were diagnosed according to the National Institute for Neurological and Communicative Diseases AD and Related Disorders Association (NIAAAA) criteria for probable $\mathrm{AD}$ [26], with probability of AD etiology based on the AD CSF biomarkers. Subjects were labeled as SCD when no abnormalities on clinical or cognitive testing were observed and the criteria for $\mathrm{MCI}$, dementia, or other medical conditions potentially causing cognitive decline were not met. To be included as controls in the current study, they had to fulfill also the following additional inclusion criteria: (1) normal AD biomarker levels and (2) preserved normal cognitive function on neuropsychological testing for at least 2 years after the first presentation at the memory clinic. The study was approved by the local medical ethics committee, and all subjects gave their written informed consent for the use of their clinical data and CSF for research purposes.

\section{Standard CSF procedures}

In line with the international biobanking consensus guidelines [27], CSF was obtained by lumbar puncture using a 25-gauge needle and a syringe and collected into 10-mL polypropylene tubes (Sarstedt, Nümbrecht, Germany). Part of the CSF was used for routine analysis, including leukocyte and erythrocyte count, glucose concentration, total protein concentration, and $A \beta_{1-42}$, total tau, and p-tau concentrations (Innotest ${ }^{\circ}$, Fujirebio, Gent, Belgium). The ratio of CSF total tau and $A \beta_{1-42}$, measured with Innotest enzyme immunoassay, was used to determine the presence of an AD profile in CSF (CSF tau $/ A \beta_{1-42} \geq 0.52$ [24]). Within $2 \mathrm{~h}, 2 \mathrm{ml}$ CSF was centrifuged at $1800 \times g$ for $10 \mathrm{~min}$ at $4{ }^{\circ} \mathrm{C}$, transferred to new polypropylene tubes, and stored at $-20^{\circ} \mathrm{C}$ for routine biomarker analysis. The remaining CSF was processed similarly, but stored directly at $-80{ }^{\circ} \mathrm{C}$ for biobanking.

\section{Measurement of CSF $A \beta 38, A \beta 40$, and $A \beta 42$}

For this study, CSF $A \beta 42, A \beta 40$, and $A \beta 38$ concentrations were determined with Meso Scale Discovery (MSD) Abeta 3-Plex Kit (Meso Scale Diagnostic, Rockville, USA).

\section{Cognitive follow-up}

Follow-up for all patients took place by annual routine visits to the memory clinic in which physical and neurological examination and cognitive assessment were repeated. Each DLB patient underwent at least one cognitive assessment. Follow-up MMSE data were available in $51(71 \%)$ DLB patients, with a mean follow-up time of $2.7 \pm 1.8$ years. Follow-up extended up to 8 years for individual patients.

Table 1 Demographics, clinical characteristics, and CSF biomarker characteristics in DLB, AD, and controls

\begin{tabular}{|c|c|c|c|}
\hline & $\operatorname{DLB}(n=72)$ & $\mathrm{AD}(n=38)$ & Controls $(n=38)$ \\
\hline Female $(n, \%)$ & $7(10 \%)$ & $3(8 \%)$ & $5(13 \%)$ \\
\hline Age $($ mean $\pm S D)$ & $68 \pm 6$ & $68 \pm 6$ & $67 \pm 6$ \\
\hline MMSE (median [IQR]) & $23[21-26]^{\mathrm{b}}$ & $22[18-25]^{\mathrm{b}}$ & $29[28-30]$ \\
\hline APOE $\varepsilon 4$ carrier $(n, \%)$ & $39(57 \%)^{\mathrm{a}}$ & $26(72 \%)^{\mathrm{a}}$ & $12(32 \%)$ \\
\hline \multicolumn{4}{|c|}{ CSF AD biomarkers Innotest (median [IQR]) } \\
\hline$A \beta_{1-42}(\mathrm{pg} / \mathrm{ml})^{*}$ & $790[638-1040]^{\mathrm{b}, \mathrm{d}}$ & $620[562-660]^{b}$ & 1123 [1022-1291] \\
\hline t-tau $(p g / m l)$ & $306[228-368]^{\mathrm{b}, \mathrm{d}}$ & $611[498-791]^{\mathrm{b}}$ & $230[187-271]$ \\
\hline p-tau $(p g / m l)$ & $47[35-60]^{d}$ & $79[65-99]^{\mathrm{b}}$ & $44[34-50]$ \\
\hline CSF tau/Aß42 > $0.52(n, \%)$ & $23(33 \%)^{\mathrm{b}, \mathrm{d}}$ & $38(100 \%)^{b}$ & $0(0 \%)$ \\
\hline \multicolumn{4}{|c|}{ CSF A $\beta$ peptides MSD (mean \pm SD) } \\
\hline $\mathrm{A} \beta 42(\mathrm{pg} / \mathrm{ml})$ & $441 \pm 185^{\mathrm{b}, \mathrm{d}}$ & $304 \pm 71^{b}$ & $692 \pm 205$ \\
\hline$A \beta 40(p g / m l)$ & $5432 \pm 1340^{\mathrm{a}}$ & $5897 \pm 1066$ & $6243 \pm 1500$ \\
\hline$A \beta 38(p g / m l)$ & $2247 \pm 638^{\mathrm{a}, \mathrm{c}}$ & $2524 \pm 547$ & $2676 \pm 703$ \\
\hline$A \beta 42 / A \beta 40$ ratio & $0.08 \pm 0.03^{\mathrm{b}, \mathrm{d}}$ & $0.05 \pm 0.01^{b}$ & $0.11 \pm 0.02$ \\
\hline$A \beta 42 / A \beta 38$ ratio & $0.20 \pm 0.07^{\mathrm{b}, \mathrm{d}}$ & $0.12 \pm 0.03^{b}$ & $0.26 \pm 0.04$ \\
\hline A $\beta 38 / A \beta 40$ ratio & $0.41 \pm 0.03^{a, c}$ & $0.43 \pm 0.04$ & $0.43 \pm 0.02$ \\
\hline
\end{tabular}

Data are presented as mean \pm SD, median [interquartile range], or $n$ (\%). Differences between groups were assessed with ANOVA, $X^{2}$, and Kruskal-Wallis $H$ tests where appropriate. For CSFA $\beta$ peptides, differences between diagnostic groups were assessed using ANOVA corrected for multiple comparisons using a false discovery rate (FDR) correction

Abbreviations: $A \beta 42$ amyloid $\beta_{1-42}$ determined with MSD ELISA assay, $A \beta 40$ amyloid $\beta_{1-40}$ determined with MSD ELISA assay, A 338 amyloid $\beta_{1-38}$ determined with MSD ELISA assay, AD Alzheimer's disease, DLB dementia with Lewy bodies, MMSE mini-mental state examination, MSD Meso Scale Discovery ${ }^{a} p<0.05$ compared to controls; ${ }^{b} p<0.001$ compared to controls; ${ }^{c} p<0.05$ compared to $A D$; ${ }^{d} p<0.001$ compared to $A D$

*Levels of Innotest $A \beta_{1-42}$ were drift corrected [28] 


\section{Statistical analyses}

Analyses were performed using $\mathrm{R}$ (version 3.2.5, R Development Core Team 2010). To assess group differences at baseline, univariate analysis of variance (ANOVA), $\chi^{2}$, and Kruskal-Wallis $H$ tests were performed where appropriate. Differences in CSF A $\beta$ peptide levels between groups were compared using ANOVA corrected for age and sex in conjunction with Student $t$ tests corrected for multiple comparisons using a false discovery rate (FDR) correction. We assessed associations of the CSF A $\beta$ peptides using Pearson correlations. Results were corrected for multiple comparisons using FDR correction.

Associations between CSF A $\beta$ peptides and MMSE score at baseline and longitudinal changes over time were assessed with linear mixed models. The models included terms for time (years), CSF A $\beta$ peptide measures, and an interaction term of CSF $A \beta$ peptide measure $x$ time as independent variables and MMSE score as the dependent variable and were adjusted for age, sex, and education. For all models, a random intercept and slope were assumed. $A \beta$ peptide levels were transformed to $z$ scores. A beta coefficient of $1(\beta=1)$ therefore implies that a 1 standard deviation increase in CSF A $\beta$ peptide was associated with a 1-point increase in MMSE score. A $p$ value $<0.05$ was considered significant.

\section{Results}

\section{Patient characteristics}

Table 1 displays the demographics, clinical characteristics, and CSF biomarker characteristics per diagnostic group. Diagnostic groups had similar age and sex distribution, showing effective matching. Dementia patients (DLB and AD) showed lower MMSE scores at baseline compared to controls $(p<0.001)$. There were more APOE\&4 carriers in DLB and AD groups compared to controls $(p<0.05)$.

\section{CSF $A \beta$ peptides in DLB, $A D$, and controls}

DLB patients had lower CSF levels of all three $A \beta$ peptides $(\mathrm{A} \beta 382247 \pm 638 \mathrm{pg} / \mathrm{ml}, \mathrm{A} \beta 405432 \pm 1340 \mathrm{pg} / \mathrm{ml}$, A $\beta 42441 \pm 185 \mathrm{pg} / \mathrm{ml})$ compared to controls $(p<0.05)$, whereas $\mathrm{AD}$ patients showed only lower levels of $\mathrm{A} \beta 42$ $(304 \pm 71 \mathrm{pg} / \mathrm{ml})$ compared to controls $(p<0.001)$. Moreover, DLB patients had lower levels of A $\mathrm{B} 38$ as compared with $\mathrm{AD}(p<0.05$, Table 1 and Fig. $2 \mathrm{a}-\mathrm{c})$.

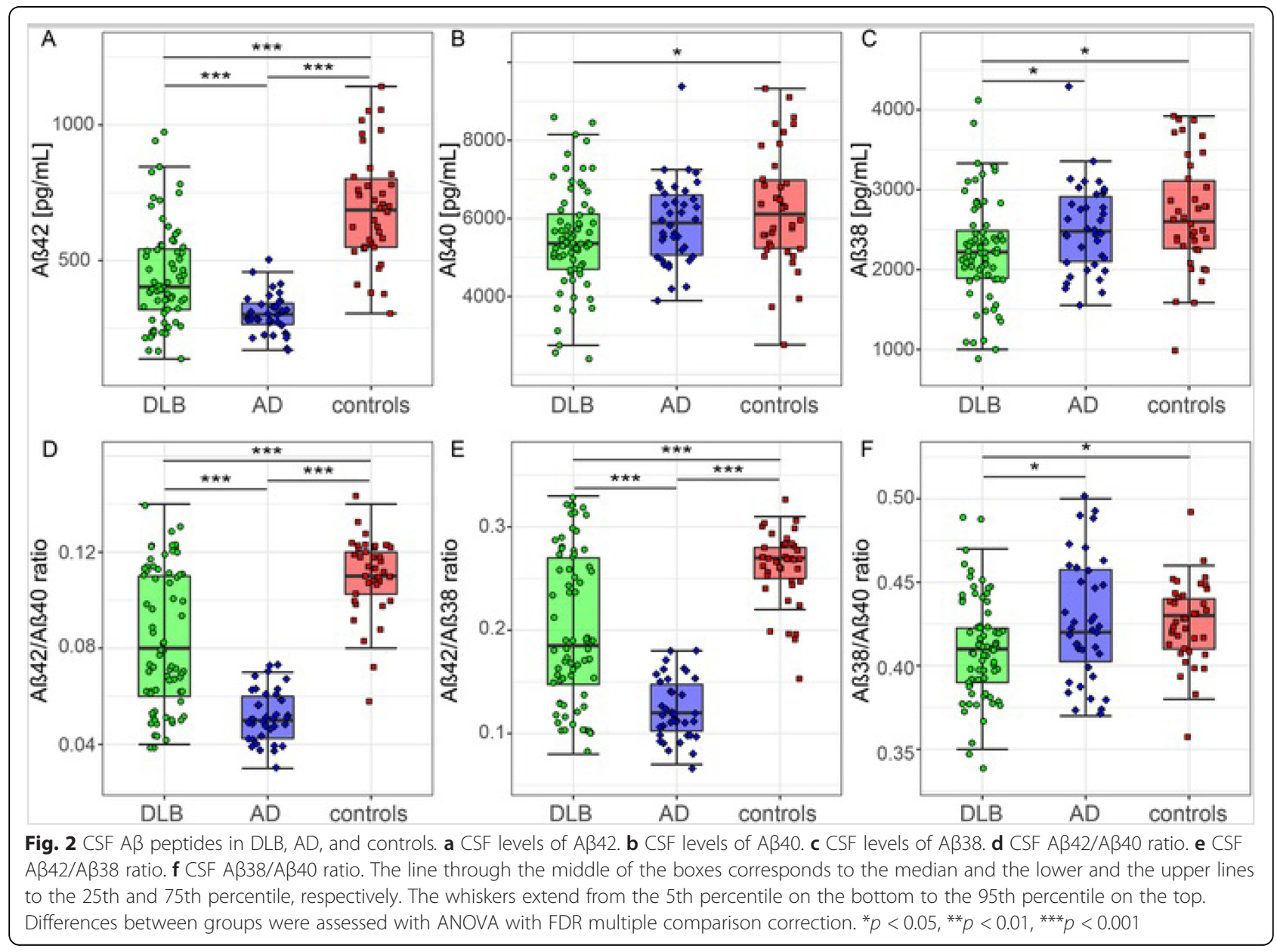


Consequently, the ratios $A \beta 42 / A \beta 40$ and $A \beta 42 / A \beta 38$ were the lowest in $\mathrm{AD}$ and the highest in controls, and DLB patients had values in between $(p<0.001$ compared to $\mathrm{AD}$ and controls). $\mathrm{A} \beta 38 / \mathrm{A} \beta 40$ ratio was the lowest in DLB $(p<0.05$ compared to AD and controls, Table 1 and Fig. $2 d-f)$. Associations between $A \beta$ peptides in CSF are shown in Additional file 1: Table S1. Throughout all investigated diagnostic groups, the different $A \beta$ peptide levels were strongly positively correlated to each other (all $r>0.5$ ), especially the correlation between A $\beta 40$ and $\mathrm{A} \beta 38$ was strong $(0.93<r<.98, p<0.001)$. In $\mathrm{AD}$ and DLB patients, the $A \beta 42 / A \beta 40$ and $A \beta 42 / A \beta 38$ ratios were inversely associated with the ratio between tau and A $\beta 42(-0.5<r<-0.71, p<0.05)$. In controls, however, no associations were found. In AD, but not in DLB, the $A \beta 38 / A \beta 40$ ratio correlated positively with the tau/A $\beta 42$ ratio $(r=0.52, p<0.05)$. No associations were found between any of the A $\beta$ peptides and age and sex.

\section{CSF $A \beta$ peptides in DLB subgroups}

To determine whether the observed differences in CSF $\mathrm{A} \beta$ peptides were influenced by the presence of comorbid AD pathology, we analyzed CSF A $\beta$ peptide levels in DLB patients with a CSF profile compatible with AD (DLB AD+, $n=23$ ) and in DLB patients with a normal CSF profile (DLB AD-, $n=48$ ). DLB AD+ patients were older and were more often $\mathrm{APOE} \varepsilon 4$ carrier than DLB AD- patients (Additional file 1: Table S2). CSF A 442 levels were lower in the DLB AD+ group compared to the DLB AD- group ( $p<0.001$, Fig. 3a) as was to be expected. There were no differences in levels of CSF A 440 and CSF $A \beta 38$ between DLB AD+ and DLB AD- patients $(p>0.05$, Fig. $3 \mathrm{~b}, \mathrm{c})$. Furthermore, the $A \beta 42 / A \beta 40$ and $A \beta 42 / A \beta 38$ ratios were lower in the DLB AD+ group compared to the DLB AD- group $(p<0.001$, Fig. 3d, e), while no difference was found for the $A \beta 38 / A \beta 40$ ratio $(p>0.05$, Fig. 3f). Next, we investigated whether APOE genotype influences CSF levels of $A \beta$ peptides in DLB patients. CSF levels of $A \beta 42$ were lower in DLB patients carrying two APOE $\varepsilon 4$ alleles than in non-carriers $(p<0.05$, Fig. $4 \mathrm{a})$, and the $\mathrm{A} \beta 42 / \mathrm{A} \beta 40$ and $\mathrm{A} \beta 42 / \mathrm{A} \beta 38$ ratios were lower in APOE $\varepsilon 4$ carriers compared to non-carriers in a gene dose-dependent manner $(p<0.05$, Fig. $4 \mathrm{~d}, \mathrm{e})$. In contrast, CSF levels of A $\beta 40$, $\mathrm{A} \beta 38$, and $\mathrm{A} \beta 38 / \mathrm{A} \beta 40$ ratios were similar in all $\mathrm{APOE}$ subgroups and did not show dose-dependent differences (Fig. 4b, c, f).
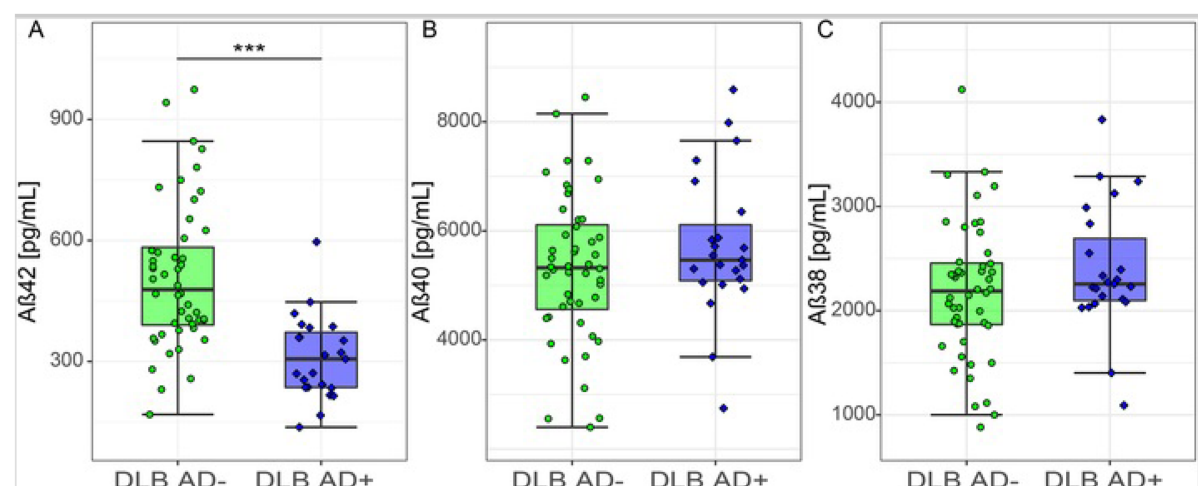

D
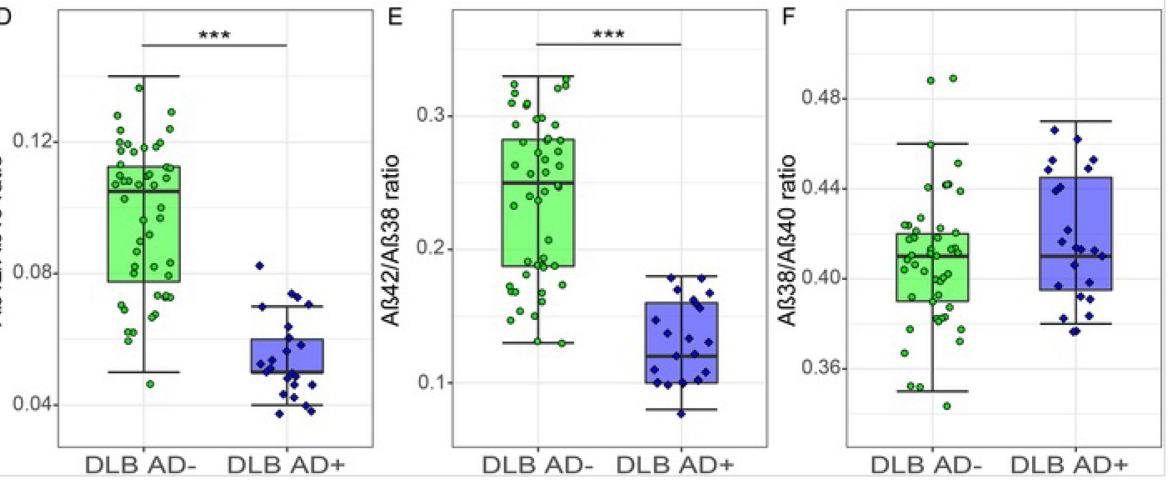

Fig. 3 CSF A $\beta$ peptides stratified by CSF tau/AB42 ratio in DLB. a CSF levels of A 42 . b CSF levels of A 440 . c CSF levels of A 338. $\mathbf{d}$ CSF A $A 42$ / $A \beta 40$ ratio. e CSF $A \beta 42 / A \beta 38$ ratio. $\mathbf{f}$ CSF $A \beta 38 / A \beta 40$ ratio. The line through the middle of the boxes corresponds to the median and the lower and the upper lines to the 25th and 75th percentile, respectively. The whiskers extend from the 5th percentile on the bottom to the 95th percentile on the top. For visualization purposes, the AD and control groups are also presented. Differences between DLB AD- and DLB AD+ were assessed with ANOVA corrected for age and sex. ${ }^{*} p<0.05,{ }^{* *} p<0.01,{ }^{* *} p<0.001$ 


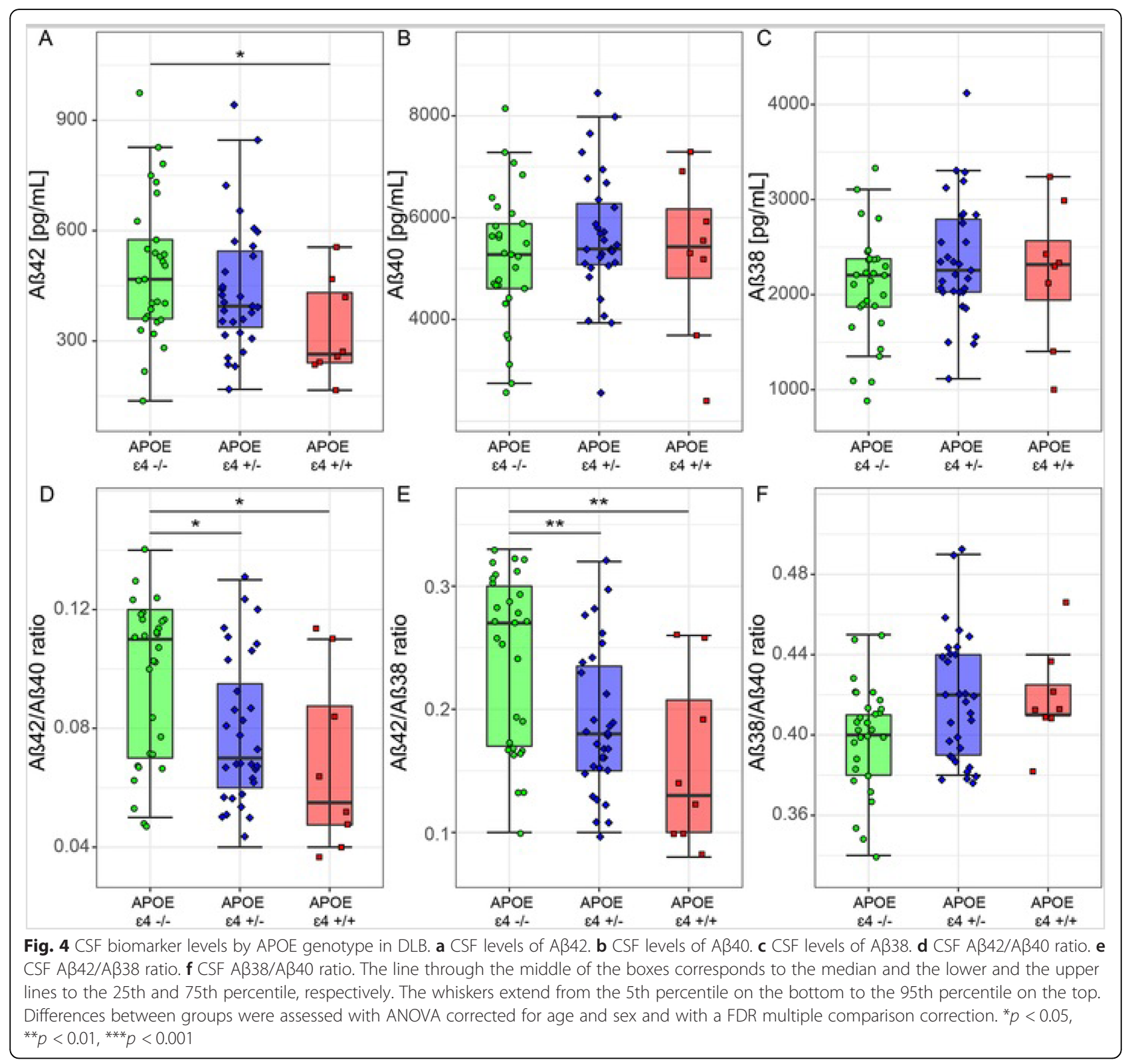

\section{CSF $A \beta$ peptides and cognitive decline}

Table 2 and Fig. 5 demonstrate the results of linear mixed-effects models, which we used to test associations between CSF A $\beta$ peptide levels and cognitive decline as examined by longitudinal change in MMSE score in DLB patients, adjusted for age, sex, and education. Lower levels of CSF A $\beta 42$, CSF A $\beta 40$, and CSF A 338 were associated with lower baseline MMSE scores $(\mathrm{A} \beta 42: \beta=1.02, \mathrm{SE}=0.45, p<0.05 ; \mathrm{A} \beta 40: \beta=1.11, \mathrm{SE}=$ 0.43, $p<0.05$; $\mathrm{A} \beta 38: \beta=1.03, \mathrm{SE}=0.43, p<0.05)$, but CSF A $\beta$ peptide levels were not associated with cognitive decline over time (interaction effect CSF A $\beta$ peptide level $\times$ time, $p>0.05$ ). In addition, no associations between $\mathrm{A} \beta$ peptide ratios and MMSE scores either at baseline or over time were found.

\section{Discussion}

The main finding of this study is lower CSF levels of $A \beta 42, A \beta 40$, and $A \beta 38$ peptides in a large group of DLB patients compared with controls, whereas AD patients presented with lower levels of CSF A $\beta 42$ only, suggesting disease-specific aberrations in amyloid metabolism. Second, the observed differences in $A \beta 38$ and $A \beta 40$ were independent of co-morbid $\mathrm{AD}$ pathology and APOE genotype. Finally, low levels of all three CSF A $\beta$ peptides were associated with more pronounced cognitive decline.

The finding of a selective drop of CSF $A \beta 42$ in $A D$, whereas in DLB lower levels of CSF A $\beta 42$ were accompanied by lower overall $A \beta$ peptide levels, confirms previous observations by other groups [18-23]. These 
Table 2 Association of baseline CSF A $\beta$ peptide levels with cognition over time in DLB

\begin{tabular}{|c|c|c|c|c|}
\hline \multirow[b]{2}{*}{ Predictors } & \multicolumn{2}{|c|}{ MMSE score at baseline } & \multicolumn{2}{|c|}{ Change in MMSE over time } \\
\hline & $\overline{\beta(\mathrm{SE})}$ & $p$ & $\overline{\beta(\mathrm{SE})}$ & $p$ \\
\hline$\overline{A \beta 42}$ & $1.02(0.45)$ & $0.027^{*}$ & $0.01(0.19)$ & 0.929 \\
\hline$A \beta 40$ & $1.11(0.43)$ & $0.012^{*}$ & $-0.13(0.22)$ & 0.551 \\
\hline$A \beta 38$ & $1.03(0.43)$ & $0.020^{*}$ & $-0.11(0.22)$ & 0.618 \\
\hline$A \beta 42 / A \beta 40$ ratio & $0.29(0.49)$ & 0.556 & $0.19(0.20)$ & 0.340 \\
\hline$A \beta 42 / A \beta 38$ ratio & $0.25(0.48)$ & 0.594 & $0.18(0.20)$ & 0.383 \\
\hline $\mathrm{A} \beta 38 / \mathrm{A} \beta 40$ ratio & $0.43(0.44)$ & 0.331 & $0.00(0.23)$ & 0.976 \\
\hline
\end{tabular}

Data are presented as standardized estimates ( $\beta$ ) with their standard error (SE) and $p$ value. Linear mixed models were used with terms for time (years), CSF $A \beta$ peptide measures, and an interaction term of CSF $A \beta$ peptide measure $x$ time as independent variables and MMSE score as the dependent variable. For all models, a random intercept and slope were assumed. $A \beta$ peptide levels were transformed to $z$-scores. A beta coefficient of one $(\beta=1)$ therefore implies that a 1 standard deviation increase in CSF A $\beta$ peptide was associated with a 1-point increase in MMSE score. The models (one model per CSF A $\beta$ peptide) were adjusted for age, sex, and education

Abbreviations: $A \beta 42$ amyloid $\beta_{1-42}$ determined with MSD ELISA assay, $A \beta 40$

amyloid $\beta_{1-40}$ determined with MSD ELISA assay, $A \beta 38$ amyloid $\beta_{1-38}$ determined with MSD ELISA assay

${ }^{*} p<0.05$

findings are also in line with a study in Parkinson's disease (PD) showing that levels $A \beta 42, A \beta 40$ and $A \beta 38$ were lower in CSF of early PD patients compared with controls [29]. The mechanisms underlying the different CSF A $\beta$ peptide pattern in DLB compared to AD are unknown. An explanation could be that other non-ADspecific mechanisms affect global levels of all three $A \beta$ peptides in the brain in DLB patients, since $A \beta 40$ and A 338 levels in CSF are not expected to decrease as a result of AD pathology. To investigate this, we evaluated the effect of co-morbid AD pathology reflected by a CSF AD biomarker profile on CSF A $\beta$ peptides in DLB. We found no differences in the levels of CSF A 340 and A 338 between DLB patients with co-morbid AD pathology and DLB patients without co-morbid AD pathology, suggesting that lower CSF levels of $A \beta 40$ and A 338 levels in DLB were independent of co-morbid AD pathology. The finding of an association between CSF tau/A $\beta 42$ and CSF $A \beta 38 / A \beta 40$ in AD, whereas no association was observed in DLB, further supports the hypothesis that amyloid- $\beta$ metabolism is different in DLB versus $A D$. Neither did we find an effect of APOE $\varepsilon 4$ genotype on CSF $\mathrm{A} \beta 40$ and $\mathrm{A} \beta 38$ in DLB patients. A previous study reported an association between APOE $\varepsilon 4$ genotype and reduced levels of CSF A 342 [30]. We observed only lower CSF A $\beta 42$ levels in DLB patients carrying two APOE $\varepsilon 4$ alleles. Our data seem to suggest that lower levels of all three $A \beta$ peptides are likely due to DLB-specific mechanisms and that at least some of the mechanisms of action for APOE $\varepsilon 4$ may be distinct from amyloidogenesis in DLB. Other researchers have similarly noted that APOE $\varepsilon 4$ is associated with a greater severity of Lewy body pathology independent of co-morbid AD pathology [31]. Finally, we evaluated the effect of CSF $A \beta$ peptides on cognitive decline in DLB patients. Low levels of CSF A $\beta$ peptides were associated with lower MMSE scores at baseline, while low levels of CSF A $\beta$ peptides were not associated with a steeper rate of cognitive decline over time. This is consistent with previous studies that showed CSF A $\beta 42$ levels are inversely associated with cognitive function in DLB $[23,32]$. Other studies have also demonstrated that co-morbid AD pathology was associated with more rapid cognitive decline over time in $\operatorname{DLB}[5,8,9]$.

Overall, our results might suggest that different pathogenic biological processes are involved in $A \beta$ peptiderelated amyloidogenesis in DLB versus $A D$. In $A D$, increased production and/or failure of clearance of $A \beta 42$ lead to $A \beta$ aggregation $[11,12]$ and $A \beta$ aggregation subsequently result in low A $\beta 42$ levels in CSF. DLB patients, however, showed in addition to low CSF A 342 levels also lower levels of CSF $A \beta 40$ and $A \beta 38$. The mechanism underlying the lower levels of all three $A \beta$ peptides are likely related to dysregulation in amyloid precursor protein (APP) pathways. It is important to note that studies investigating APP processing in DLB are limited and therefore it is only possible to speculate about the explanations for our findings. APP processing is a complex process, and many factors are involved in the posttranslational cleavage of APP into A $\beta$ peptides. Cleavage of APP by $\alpha$-secretase produces APP $\alpha$, whereas cleavage by $\beta$-secretase generates $\mathrm{APP} \beta$ and a C-terminal fragment (C99), which subsequently can be further metabolized by $\gamma$-secretase to produce $A \beta$ peptides $[11,12]$. Preclinical studies suggest that lower neuronal activity leads to reduced APP processing and consequently influences levels of $A \beta$ peptides in the brain $[33,34]$. In EEG studies, DLB patients showed marked slow-wave activity and more pronounced abnormalities compared with AD patients suggesting that reduced neuronal activity is prominent in DLB $[35,36]$. In addition, synaptic dysfunction and, as a consequence, neurotransmitter deprivation and reduced neuronal activity could be directly linked to $\alpha$-synuclein aggregates at synapses [37]. More direct evidence supporting the hypothesis of decreased APP processing in DLB is provided by a recent study that showed lower CSF levels of $\mathrm{APP} \alpha$ and APP $\beta$ in DLB compared with AD and healthy controls [38]. Thus, the reduced activity in neuronal networks in DLB might result in diminished production of all $A \beta$ peptides, including $A \beta 42$. These results highlight the need for further studies into APP processing and $A \beta$ accumulation in DLB.

Among the strengths of our study was the relatively large group $(n=72)$ of probable DLB patients, which were compared to age- and sex-matched AD patients 


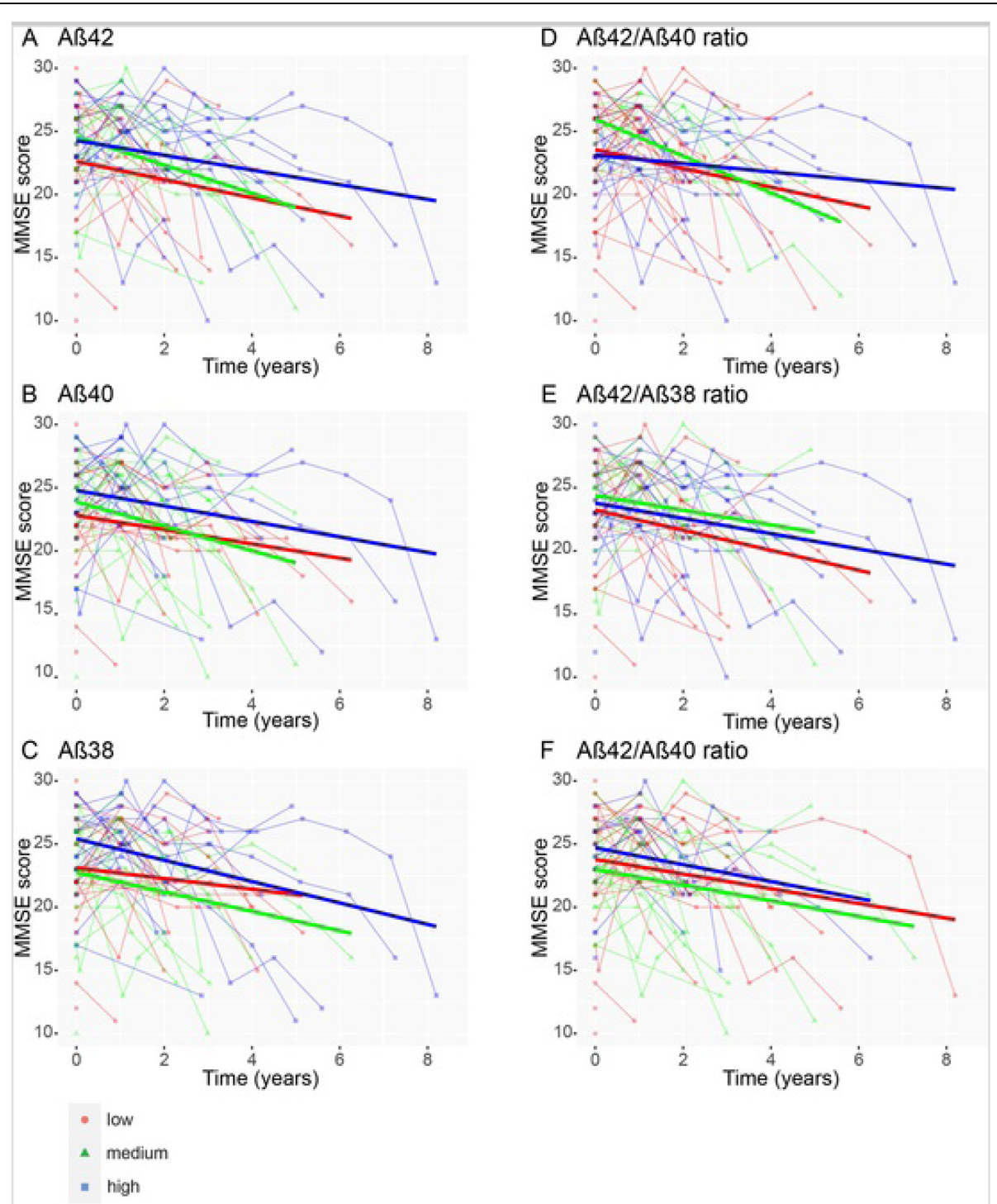

Fig. 5 CSF A peptide levels and cognitive decline in DLB. a Associations between baseline CSF A 42 levels and subsequent cognitive decline in the DLB group $(n=72)$ as measured by Mini-Mental State Examination (MMSE) score. b CSF A 340 . c CSF A 338. d CSF A $42 / A \beta 40$ ratio. e CSF $A \beta 42 / A \beta 38$ ratio. f CSF $A \beta 38 / A \beta 40$ ratio. Associations are shown using linear regression lines, with all DLB patients classified into tertile groups (low, medium, high) according to their CSF A $\beta$ peptide levels for visualization purposes, but for the linear mixed model statistical analysis, continuous CSF A $\beta$ peptide levels were used. Results were essentially the same when using A $\beta$ peptide level tertiles as a categorical predictor

and controls. Deep clinical phenotyping and clinical follow-up of all patients and controls were available. Furthermore, the etiological diagnosis was either supported by biomarkers or confirmed by autopsy. We therefore consider it unlikely that our results are significantly biased by clinical misdiagnosis. Controls included in the present study had normal CSF AD biomarkers at baseline and preserved normal cognitive function on neuropsychological testing. Using these inclusion criteria, we could almost certainly rule out AD. However, we were not able to exclude other causes of dementia since no reliable biomarkers are available yet. Another limitation is that data on $A \beta$ peptide levels in CSF from patients with PD and PD patients with cognitive impairment were not available for the present study. Therefore, it is not possible at this time to incorporate the results into the full spectrum of Lewy body disease. Finally, we used the ratio of CSF tau/A $\beta 42 \geq 0.52$ as a surrogate measure for co-morbid $\mathrm{AD}$ pathology. It would be interesting to investigate the putative relevance of the novel AT(N) framework as a classification system for co-morbid AD pathology in DLB [39].

\section{Conclusion}

Our results strongly suggest the presence of distinct CSF $A \beta$ peptide profiles in DLB and AD, suggesting disease- 
specific aberrations in amyloid metabolism. In particular, the isolated drop of CSF A $\beta 42$ in AD is likely a consequence of aggregation and deposition of $A \beta$ in the brain. In contrast, DLB comes with reductions in all three CSF $A \beta$ peptides, independent of co-morbid AD pathology or APOE genotype. These findings suggest that $A \beta$ metabolism is affected in DLB, even in the absence of comorbid AD pathology. Studies to elucidate the link between $\alpha$-synuclein pathology and $A \beta$ metabolism are vital to the understanding of $A \beta$ peptide-related amyloidogenesis in DLB and could lead to novel therapeutic approaches.

\section{Supplementary information}

Supplementary information accompanies this paper at https://doi.org/10. 1186/s13195-019-0537-5

Additional file 1: Table S1. Associations between A $\beta$ peptides in CSF. Table S2. Demographics, clinical characteristics and CSF biomarker characteristics stratified by CSF. (DOCX $18 \mathrm{~kb}$ )

\section{Abbreviations}

Aß: Amyloid- $\beta$; AD: Alzheimer's disease; APOE: Apolipoprotein E; APP: Amyloid precursor protein; CSF: Cerebrospinal fluid; DLB: Dementia with Lewy bodies; DAT-SPECT: (123) I-FP-CIT-SPECT scan

\section{Acknowledgements}

The authors thank Harry Twaalfhoven for the analysis of the CSF samples. Research of the Alzheimer Center Amsterdam is part of the neurodegeneration research program of Amsterdam Neuroscience. The Alzheimer Center Amsterdam is supported by Stichting Alzheimer Nederland and Stichting VUmc fonds. The clinical database structure was developed with funding from Stichting Dioraphte.

\section{Authors' contributions}

IS drafted the manuscript and analyzed/interpreted the data. WMF drafted the manuscript and analyzed/interpreted the data. PS revised the manuscript and interpreted the data. CET revised the manuscript and interpreted the data. AWL drafted the manuscript, analyzed/interpreted the data, and supervised the project. All authors read and approved the final manuscript.

\section{Funding}

This study is further funded by the Memorabel grant programme of the Nederlands Organisation of Health Research and Development (ZonMW grant: 733050509). The funder had no role in the study design, data collection and analysis, decision to publish, or preparation of the manuscript.

\section{Availability of data and materials}

The datasets used and/or analyzed during the current study are available from the corresponding author on reasonable request.

\section{Ethics approval and consent to participate}

The study was approved by the local Medical Ethical Committee. All patients provided written informed consent for their clinical data and CSF to be used for research purposes.

\section{Consent for publication}

Not applicable.

\section{Competing interests}

Wiesje M van der Flier performs contract research for Boehringer Ingelheim. Research programs of Wiesje M. van der Flier have been funded by ZonMW, NWO, EU-FP7, Alzheimer Nederland, CardioVascular Onderzoek Nederland, stichting Dioraphte, Gieskes-Strijbis fonds, Boehringer Ingelheim, Piramal Neuroimaging, Roche BV, and Janssen Stellar. All funding is paid to her institution. Philip Scheltens has served as a consultant for Wyeth-Elan, Genentech,
Danone, and Novartis and received funding for travel from Pfizer, Elan, Janssen, and Danone Research. Charlotte E. Teunissen is a member of the Innogenetics International Advisory Boards of Fujirebio/Innogenetics and Roche. Inger van Steenoven and Afina W. Lemstra declare that they have no competing interests.

\section{Author details}

'Alzheimer Center Amsterdam, Department of Neurology, Amsterdam Neuroscience, Vrije Universiteit Amsterdam, Amsterdam UMC, De Boelelaan 1118, 1081 HV Amsterdam, The Netherlands. ${ }^{2}$ Department of Epidemiology and Biostatistics, Amsterdam Neuroscience, Vrije Universiteit Amsterdam, Amsterdam UMC, Amsterdam, The Netherlands. ${ }^{3}$ Neurochemistry Laboratory and Biobank, Department of Clinical Chemistry, Amsterdam Neuroscience, Vrije Universiteit Amsterdam, Amsterdam UMC, Amsterdam, The Netherlands.

Received: 22 March 2019 Accepted: 9 September 2019

Published online: 10 October 2019

\section{References}

1. Walker Z, Possin KL, Boeve BF, Aarsland D. Lewy body dementias. Lancet. 2015;386(10004):1683-97.

2. McKeith IG, Boeve BF, Dickson DW, Halliday G, Taylor JP, Weintraub D, et al. Diagnosis and management of dementia with Lewy bodies: fourth consensus report of the DLB Consortium. Neurology. 2017;89(1):88-100.

3. Vekrellis K, Xilouri M, Emmanouilidou E, Rideout HJ, Stefanis L. Pathological roles of alpha-synuclein in neurological disorders. Lancet Neurol. 2011; 10(11):1015-25.

4. Howlett DR, Whitfield D, Johnson M, Attems J, O'Brien JT, Aarsland D, et al. Regional multiple pathology scores are associated with cognitive decline in Lewy body dementias. Brain Pathol. 2015;25(4):401-8.

5. Irwin DJ, Grossman M, Weintraub D, Hurtig HI, Duda JE, Xie SX, et al. Neuropathological and genetic correlates of survival and dementia onset in synucleinopathies: a retrospective analysis. Lancet Neurol. 2017;16(1):55-65.

6. van Steenoven I, Aarsland D, Weintraub D, Londos E, Blanc F, van der Flier WM, et al. Cerebrospinal fluid Alzheimer's disease biomarkers across the spectrum of Lewy body diseases: results from a large multicenter cohort. J Alzheimers Dis. 2016:54(1):287-95.

7. Merdes AR, Hansen LA, Jeste DV, Galasko D, Hofstetter CR, Ho GJ, et al. Influence of Alzheimer pathology on clinical diagnostic accuracy in dementia with Lewy bodies. Neurology. 2003;60(10):1586-90.

8. Lemstra AW, de Beer MH, Teunissen CE, Schreuder C, Scheltens P, van der Flier WM, et al. Concomitant AD pathology affects clinical manifestation and survival in dementia with Lewy bodies. J Neurol Neurosurg Psychiatry. 2017; 88(2):113-8.

9. Abdelnour C, van Steenoven I, Londos E, Blanc F, Auestad B, Kramberger MG, et al. Alzheimer's disease cerebrospinal fluid biomarkers predict cognitive decline in Lewy body dementia. Movement Disorders. 2016:31(8):1203-8

10. Nelson PT, Kryscio RJ, Jicha GA, Abner EL, Schmitt FA, Xu LO, et al. Relative preservation of MMSE scores in autopsy-proven dementia with Lewy bodies. Neurology. 2009;73(14):1127-33.

11. Selkoe DJ, Hardy J. The amyloid hypothesis of Alzheimer's disease at 25 years. EMBO Mol Med. 2016;8(6):595-608.

12. O'Brien RJ, Wong PC. Amyloid precursor protein processing and Alzheimer's disease. Annu Rev Neurosci. 2011;34:185-204.

13. Haass C, Selkoe DJ. Cellular processing of beta-amyloid precursor protein and the genesis of amyloid beta-peptide. Cell. 1993;75(6):1039-42.

14. Wiltfang J, Esselmann H, Bibl M, Smirnov A, Otto M, Paul S, et al. Highly conserved and disease-specific patterns of carboxyterminally truncated Abeta peptides 1-37/38/39 in addition to 1-40/42 in Alzheimer's disease and in patients with chronic neuroinflammation. J Neurochem. 2002:81(3):481-96.

15. Tapiola T, Alafuzoff I, Herukka SK, Parkkinen L, Hartikainen P, Soininen $H$ et al. Cerebrospinal fluid \{beta\}-amyloid 42 and tau proteins as biomarkers of Alzheimer-type pathologic changes in the brain. Arch Neurol. 2009;66(3):382-9.

16. Strozyk D, Blennow K, White LR, Launer LJ. CSF Abeta 42 levels correlate with amyloid-neuropathology in a population-based autopsy study. Neurology. 2003:60(4):652-6.

17. Andreasson U, Portelius $E$, Andersson ME, Blennow K, Zetterberg H. Aspects of beta-amyloid as a biomarker for Alzheimer's disease. Biomark Med. 2007;1(1):59-78. 
18. Bibl M, Mollenhauer B, Esselmann H, Lewczuk P, Klafki HW, Sparbier K, et al. CSF amyloid-beta-peptides in Alzheimer's disease, dementia with Lewy bodies and Parkinson's disease dementia. Brain. 2006;129(Pt 5: 1177-87.

19. Bibl M, Mollenhauer B, Lewczuk P, Esselmann H, Wolf S, Trenkwalder C, et al. Validation of amyloid-beta peptides in CSF diagnosis of neurodegenerative dementias. Mol Psychiatry. 2007;12(7):671-80.

20. Mollenhauer B, Esselmann H, Roeber S, Schulz-Schaeffer WJ, Trenkwalder C, Bibl M, et al. Different CSF beta-amyloid processing in Alzheimer's and Creutzfeldt-Jakob disease. J Neural Transm (Vienna). 2011;118(5):691-7.

21. Mulugeta E, Londos E, Ballard C, Alves G, Zetterberg H, Blennow K, et al. CSF amyloid beta38 as a novel diagnostic marker for dementia with Lewy bodies. J Neurol Neurosurg Psychiatry. 2011;82(2):160-4.

22. Janelidze S, Zetterberg $\mathrm{H}$, Mattsson N, Palmqvist S, Vanderstichele $\mathrm{H}$ Lindberg O, et al. CSF Abeta42/Abeta40 and Abeta42/Abeta38 ratios: better diagnostic markers of Alzheimer disease. Ann Clin Transl Neurol. 2016;3(3): 154-65.

23. Struyfs H, Van Broeck B, Timmers M, Fransen E, Sleegers K, Van Broeckhoven C, et al. Diagnostic accuracy of cerebrospinal fluid amyloid-beta isoforms for early and differential dementia diagnosis. J Alzheimers Dis. 2015;45(3):813-22.

24. Duits FH, Teunissen CE, Bouwman FH, Visser PJ, Mattsson N, Zetterberg H, et al. The cerebrospinal fluid "Alzheimer profile": easily said, but what does it mean? Alzheimer's Dementia. 2014;10(6):713-23 e2.

25. van der Flier WM, Pijnenburg YA, Prins N, Lemstra AW, Bouwman FH, Teunissen CE, et al. Optimizing patient care and research: the Amsterdam Dementia Cohort. J Alzheimers Dis. 2014;41(1):313-27.

26. McKhann GM, Knopman DS, Chertkow H, Hyman BT, Jack CR Jr, Kawas CH, et al. The diagnosis of dementia due to Alzheimer's disease: recommendations from the National Institute on Aging-Alzheimer's Association workgroups on diagnostic guidelines for Alzheimer's disease. Alzheimer's Dementia. 2011;7(3):263-9.

27. Teunissen CE, Petzold A, Bennett $J$, Berven FS, Brundin L, Comabella M, et al. A consensus protocol for the standardization of cerebrospinal fluid collection and biobanking. Neurology. 2009;73(22):1914-22.

28. Tijms BM, Willemse EAJ, Zwan MD, Mulder SD, Visser PJ, van Berckel BNM, van der Flier WM, Scheltens P, Teunissen CE. Unbiased Approach to Counteract Upward Drift in Cerebrospinal Fluid Amyloid- $\beta$ 1-42 Analysis Results. Clin Chem. 2018 Mar;64(3):576-585. https://doi.org/10.1373/ clinchem.2017.281055.

29. Alves G, Bronnick K, Aarsland D, Blennow K, Zetterberg H, Ballard C, et al. CSF amyloid-beta and tau proteins, and cognitive performance, in early and untreated Parkinson's disease: the Norwegian ParkWest study. J Neurol Neurosurg Psychiatry. 2010;81(10):1080-6.

30. Vijayaraghavan S, Maetzler W, Reimold M, Lithner CU, Liepelt-Scarfone I, Berg D, et al. High apolipoprotein E in cerebrospinal fluid of patients with Lewy body disorders is associated with dementia. Alzheimer's Dementia. 2014;10(5):530-40 e1.

31. Dickson DW, Heckman MG, Murray ME, Soto Al, Walton RL, Diehl NN, et al, APOE epsilon4 is associated with severity of Lewy body pathology independent of Alzheimer pathology. Neurology. 2018;91(12):e1182-e95.

32. Reesink FE, Lemstra AW, van Dijk KD, Berendse HW, van de Berg WD, Klein $M$, et al. CSF alpha-synuclein does not discriminate dementia with Lewy bodies from Alzheimer's disease. J Alzheimers Dis. 2010;22(1):87-95.

33. Kamenetz F, Tomita T, Hsieh H, Seabrook G, Borchelt D, Iwatsubo T, et al. APP processing and synaptic function. Neuron. 2003;37(6):925-37.

34. Cirrito JR, Yamada KA, Finn MB, Sloviter RS, Bales KR, May PC, et al. Synaptic activity regulates interstitial fluid amyloid-beta levels in vivo. Neuron. 2005; 48(6):913-22.

35. van der Zande JJ, Gouw AA, van Steenoven I, Scheltens P, Stam CJ, Lemstra AW. EEG characteristics of dementia with Lewy bodies, Alzheimer's disease and mixed pathology. Front Aging Neurosci. 2018;10:190

36. Bonanni L, Thomas A, Tiraboschi P, Perfetti B, Varanese S, Onofrj M. EEG comparisons in early Alzheimer's disease, dementia with Lewy bodies and Parkinson's disease with dementia patients with a 2-year follow-up. Brain. 2008;131(Pt 3:690-705.

37. Schulz-Schaeffer WJ. The synaptic pathology of alpha-synuclein aggregation in dementia with Lewy bodies, Parkinson's disease and Parkinson's disease dementia. Acta Neuropathol. 2010;120(2):131-43.

38. Paterson RW, Slattery CF, Poole T, Nicholas JM, Magdalinou NK, Toombs J, et al. Cerebrospinal fluid in the differential diagnosis of Alzheimer's disease: clinical utility of an extended panel of biomarkers in a specialist cognitive clinic. Alzheimers Res Ther. 2018;10(1):32.

39. Jack CR Jr, Bennett DA, Blennow K, Carrillo MC, Dunn B, Haeberlein SB, et al. NIA-AA research framework: toward a biological definition of Alzheimer's disease. Alzheimer's Dementia. 2018;14(4):535-62.

\section{Publisher's Note}

Springer Nature remains neutral with regard to jurisdictional claims in published maps and institutional affiliations.
Ready to submit your research? Choose BMC and benefit from:

- fast, convenient online submission

- thorough peer review by experienced researchers in your field

- rapid publication on acceptance

- support for research data, including large and complex data types

- gold Open Access which fosters wider collaboration and increased citations

- maximum visibility for your research: over $100 \mathrm{M}$ website views per year

At $\mathrm{BMC}$, research is always in progress.

Learn more biomedcentral.com/submissions 